\title{
Clinicopathological and molecular study of 10 salivary gland clear cell carcinomas, with emphasis on rare cases with high grade transformation and occurring in uncommon sites
}

\author{
Lanlan Xuan ${ }^{1,2}$, Suxia Wang ${ }^{3}$, Jianguo Wei $^{4}$, Jianwei Yuan ${ }^{5}$ and Honggang Liu ${ }^{2 *}$ (D)
}

\begin{abstract}
Background: As a rare salivary gland malignancy, clear cell carcinoma (CCC) is easily misdiagnosed. This study identified the features that allow better recognition of the clinicopathological and molecular characteristics and the prognosis of CCC, focusing on high-grade transformation (HGT) in this tumor and cases arising in uncommon sites.

Methods: Clinicopathological and follow-up data for 10 CCC samples were retrieved. Immunohistochemical (IHC) staining was performed, and fluorescence in situ hybridization (FISH) was used to detect EWSR1 gene rearrangements, EWSR1-ATF1 gene fusions, and MAML2 gene rearrangements.

Results: Histologically, typical CCCs comprised bland polygonal or round cells with clear cytoplasm. In contrast with typical CCCs, HGT tumor cells exhibited nuclear pleomorphism, high nuclear-to-cytoplasmic ratios, high mitotic activity, and necrosis. Rare morphologic features such as pseudopapillae, gland-like spaces, and entrapped ducts were also observed. Occasionally, tumors involving the oral cavity might arise from the overlying epithelium of the mucosal surface. Immunohistochemically, all the cases expressed p63, p40, and CK5/6, while myoepithelial-related markers were uniformly negative in all cases. HGT exhibited a wild type p53 expression pattern. FISH demonstrated EWSR1 rearrangement (10/10) and EWSR1-ATF1 fusion (4/5); however, MAML2 remained intact (0/3).

Conclusions: CCCS with HGT or occurring in uncommon sites are extremely rare. Combining morphology based IHC and molecular detection provided reliable evidence that the HGT component represented a transformation of CCC rather than the coexistence of another tumor and helped differentiating CCCs in uncommon sites from their mimics, avoiding potential misdiagnosis and inappropriate therapy. The overall prognosis for CCCs is good, except for the HGT cases, which needed continued treatment.
\end{abstract}

Keywords: Clear cell carcinoma, Hyalinizing, High-grade transformation, EWSR1, ATF1, MAML2

\footnotetext{
* Correspondence: liuhg1125bjtr@126.com

${ }^{2}$ Department of Pathology, Beijing Tongren Hospital, Capital Medical

University, Beijing Key Laboratory of Head and Neck Molecular Diagnostic

Pathology, Beijing 100730, China

Full list of author information is available at the end of the article
}

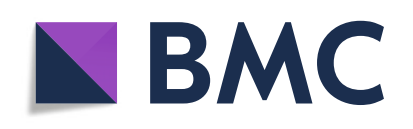

(0) The Author(s). 2022 Open Access This article is licensed under a Creative Commons Attribution 4.0 International License, which permits use, sharing, adaptation, distribution and reproduction in any medium or format, as long as you give appropriate credit to the original author(s) and the source, provide a link to the Creative Commons licence, and indicate if changes were made. The images or other third party material in this article are included in the article's Creative Commons licence, unless indicated otherwise in a credit line to the material. If material is not included in the article's Creative Commons licence and your intended use is not permitted by statutory regulation or exceeds the permitted use, you will need to obtain permission directly from the copyright holder. To view a copy of this licence, visit http://creativecommons.org/licenses/by/4.0/. The Creative Commons Public Domain Dedication waiver (http://creativecommons.org/publicdomain/zero/1.0/) applies to the data made available in this article, unless otherwise stated in a credit line to the data. 


\section{Background}

Clear cell carcinoma (CCC) is a low-grade salivary gland tumor (SGT), first described by Milchgrub et al. in 1994 from a series of 11 cases. CCC has the characteristic morphology of bland monomorphic tumor cells with clear cytoplasm, arranged in nests, islands, and sheets in a hyalinized stoma, which is why it was originally termed "hyalinizing clear cell carcinoma" (HCCC) [1]. CCC is typically present in the minor salivary glands of female patients aged $50-80$ years; it is indolent and rarely involves lymph nodes or develops distant metastases [2]. Over the past several years, the pathology of SGTs has become widely studied due to the interesting molecular alterations involved, and molecular genetic techniques are being increasingly utilized by pathologists in the diagnoses of SGTs. Studies have revealed that a majority of CCCs harbor a translocation $t \quad(12 ; 22)(q 13 ; q 12)$, resulting in the fusion of the EWSR1 gene (22q12) with the ATF1 gene (12q13), which in turn generates the chimeric gene EWSR1-ATF1 [3-5] that has become a hallmark molecular event for this tumor.

High grade transformation (HGT) refers to the transformation of tumor cells with conventional morphology into poorly differentiated or undifferentiated tumor cells with high grade morphology. In other words, HGT is the transformation of conventional morphology into high-grade morphology, making the tumor becomes more aggressive. CCCs with HGT are extremely rare and seldom reported in the literature [6,7], and few, if any, features associated with HGT are currently recognized in CCCs. Therefore, it is challenging to identify CCCs with HGT from other high-grade SGTs based on morphology alone. In addition, it is difficult to definitively diagnose CCCs found in uncommon sites due to the lack of distinguishing characteristics; misdiagnosing $\mathrm{CCCs}$ in uncommon sites as other malignancies with clear cell morphologic changes is common.

Here, we present a series of 10 new cases of CCC, including one HGT case and three cases occurring in uncommon sites (nasal cavity, tonsil, and maxillary sinus), followed by a literature review. The focus is on clinicopathological and molecular detection and their outcomes, paving the way for $\mathrm{CCC}$ recognition, diagnosis, and differential diagnosis in routine practice, with the aim of enhancing the understanding and treatment of this rare malignancy.

\section{Materials and methods \\ Case selection}

We searched for a total of 1669 cases of SGTs using the files of the SGT Registry at the Department of Pathology in Beijing Tongren Hospital, of which 10 cases pertained to CCC, accounting for $0.6 \%$. Among the 10 cases of CCC, six were in-house cases and four were consultation cases. The four referred cases had been submitted with preliminary diagnoses to be confirmed; of these, three cases were originally considered to be mucoepidermoid carcinoma (MEC), and one case was originally considered a myoepithelial carcinoma (MC). Available clinicopathological data of these patients were retrieved, and cases were reviewed by two pathologists (X.L.L. and L.H.G.) specializing in salivary gland neoplasms. Follow-up data were obtained via telephonic medium. This study was approved by the Institute Research Ethics Committee of Beijing Tongren Hospital (Approval No. TRECKY2021-108), and written informed consent was obtained from 9 of 10 patients, whereas consent from one patient was not obtained because of loss to follow-up.

\section{Immunohistochemistry}

All tissue samples had been fixed with 3.7\% neutral formaldehyde and then embedded in paraffin. Samples were stained with hematoxylin and eosin and automated immunohistochemistry (IHC) staining was performed on $4 \mu \mathrm{m}$-thick formalin-fixed paraffin-embedded (FFPE) sections using the Benchmark XT platform (Ventana Medical Systems Inc., Tucson, AZ) according to the manufacturer's instructions. Primary antibodies against the following proteins were purchased from Fuzhou Maixin Biotechnology Development Company (Fuzhou, China): cytokeratin 5/6 (CK5/6; clone D5/16B4), p63 (clone 4A4), p40 (clone Np63), smooth muscle actin (SMA; clone 1A4), calponin (clone CALP), S-100 protein (clone 4C4.9), SOX10 (clone EP268), GFAP (clone GA5), CD10 (clone 56C6), CD117 (clone 2E4), p16 (clone 6H12), p53 (clone MX008), and Ki-67 (clone MIB-1). CK5/6, SMA, calponin, and GFAP positivity were defined as tumor cells exhibiting cytoplasmic staining, whereas p63, p40, SOX10, p53, and Ki-67 positivity were assessed by nuclear staining, S-100 protein and p16 positivity by nuclear and cytoplasmic staining, and CD117 positivity by cytoplasmic and/or membrane staining. Less than $80 \%$ of the nuclei exhibited p53 immunoreactivity with variable staining intensities, and this was considered to be the wild type expression pattern [8]. All primary antibodies were ready-to-use and did not require additional dilutions. Immunohistochemical staining was performed using the MaxVision method. The FFPE sections were subjected to EDTA antigen retrieval followed by the addition of a primary antibody, incubation at $37^{\circ} \mathrm{C}$ for $45 \mathrm{~min}$ and rinsing with PBS. Then, the corresponding secondary antibody (MaxVision) was added to the sections, which were then incubated at $37^{\circ} \mathrm{C}$ for $15 \mathrm{~min}$ and rinsed with PBS. Next, DAB development was carried out for $5 \mathrm{~min}$. For all IHC stains, positive and negative controls were used. The staining results were assessed by two independent pathologists. 


\section{Fish}

A commercial EWSR1 break-apart probe, an MAML2 break-apart probe, and an EWSR1-ATF1 fusion probe (all from LBP Medicine Science and Technology Co., Ltd., Guangzhou, China) were used on FFPE sections. The experimental procedures were performed following manufacturer's instructions. Two hundred nonoverlapping tumor cell nuclei were observed by fluorescence microscopy (BX51; Olympus, Tokyo, Japan) for quantitative analysis. EWSR1 and MAML2 break-apart probes were considered to respond positively if $>15 \%$ of tumor cell nuclei exhibited red-green split signals ( $>$ two signal diameters apart). The presence of an isolated single red signal with a normal red-green signal (unsplit pair) was also counted as a gene rearrangement $[9,10]$. EWSR1-ATF1 fusion was considered positive if $>15 \%$ of tumor cell nuclei exhibited at least one yellow (red-green fusion) signal. Signals were assessed independently by two technicians.

\section{Results}

\section{Clinical finding}

Clinical data from the cohort are shown in Table 1. All cases were primary and included six female and four male individuals, ranging in age from 29 to 70 years (mean $=46$ years). Four CCCs occurred on the palate and one each from the left tonsil, the left maxillary sinus, root of the tongue, base of the tongue, the nasal cavity, and the submandibular gland. The main clinical symptoms included the development of a painless firm mass, epistaxis, paresthesia, ulceration, and dysphagia.

Among the cases analyzed, cases 3 (left tonsil), 5 (base of tongue), and 10 (left hard palate) documented neck lymph node dissection, and cases 3 and 10 recorded lymph node metastasis (2/15 and $1 / 16$, respectively), confirmed by pathological examinations.
Follow-up information was available for 9 patients, ranging from 7 to 80 months (mean, 33.7 months) after discharge. In Case 1, the patient was a 62-year-old woman with a 20-year history of a painless right submandibular gland mass that enlarged rapidly, causing pain during the last four months. A computed tomography chest scan at presentation showed multiple bilateral pulmonary nodules (Fig. 1). The patient underwent wide resection of the right submandibular mass, followed by chemotherapy, and was alive with the tumor at the time of writing this paper. Patients of cases 4,8 , and 10 received radiotherapy after surgery and were free of disease at follow-ups of 88,11 , and 54 months, respectively. Five patients did not undergo postoperative radiotherapy or chemotherapy, and none had recurrence or distant metastases at the last follow-up. One patient was lost to follow-up.

\section{Pathological features}

Tumor sizes ranged from $1.0 \mathrm{~cm}$ to $4.0 \mathrm{~cm}$ (median, 2.4 $\mathrm{cm}$; mean, $2.6 \mathrm{~cm}$ ), as measured along the longest axis. Tumors were firm with gray-white or tan-white cut surfaces and were relatively circumscribed but lacked encapsulation. Histologically, conventional CCCs were composed of oval, round, and polygonal cells with clear cytoplasm (Case 2; Fig. 2a, b), although some tumor cells had pale eosinophilic cytoplasm (the conventional region of Case 1; Fig. 2c). The nuclei were uniform and small, round, or oval and had irregular, indented contours with dark, condensed chromatin, and nucleoli were typically not prominent (Case 2; Fig. 2b). Tumor cells were typically arranged in nests, cords, or sheets.

However, we also observed some rare morphologies. In contrast to classic CCCs, HGT tumor cells exhibited nuclear pleomorphism, high nuclear-to-cytoplasmic ratios, high mitotic activity, and necrosis (Case 1; Fig. 3a, b), suggesting a poorly differentiated morphology. Cystic

Table 1 Clinicopathological data for 10 CCCs

\begin{tabular}{|c|c|c|c|c|c|}
\hline Case & Sex/Age $(y)$ & Site & Maximum size $(\mathrm{cm})$ & Clinical presentation & Follow-up (months) \\
\hline $1^{*}$ & $F / 68$ & Right submandi-bular gland & 4.0 & Painless firm mass, recently enlarged with pain & Alive with tumor (7) \\
\hline 2 & $\mathrm{~F} / 70$ & Nasal cavity & 2.0 & Nasal obstruction and epistaxis & Alive NED (80) \\
\hline 3 & M/48 & Left tonsil & 3.5 & Pharyngeal paresthesia & Alive NED (17) \\
\hline 4 & $M / 32$ & Left maxillary sinus & 2.5 & Epistaxis & Alive NED (88) \\
\hline 5 & $F / 62$ & Root of the tongue & 3.0 & Dysphagia & Alive NED (23) \\
\hline 6 & $F / 31$ & Base of tongue & 3.2 & Dysphagia & Alive NED (15) \\
\hline 7 & $M / 29$ & Right hard palate & 2.3 & Painless firm mass & Alive NED (8) \\
\hline 8 & $M / 29$ & Right hard palate & 1.8 & Ulceration & Alive NED (11) \\
\hline 9 & $F / 49$ & Right hard palate & 2.2 & Ulceration & NA \\
\hline 10 & $F / 37$ & Left hard palate & 1.2 & Ulceration & Alive NED (54) \\
\hline
\end{tabular}

*High-grade transformation (HGT) case

$F$ female, $M$ male, NED no evidence of disease, NA not available 


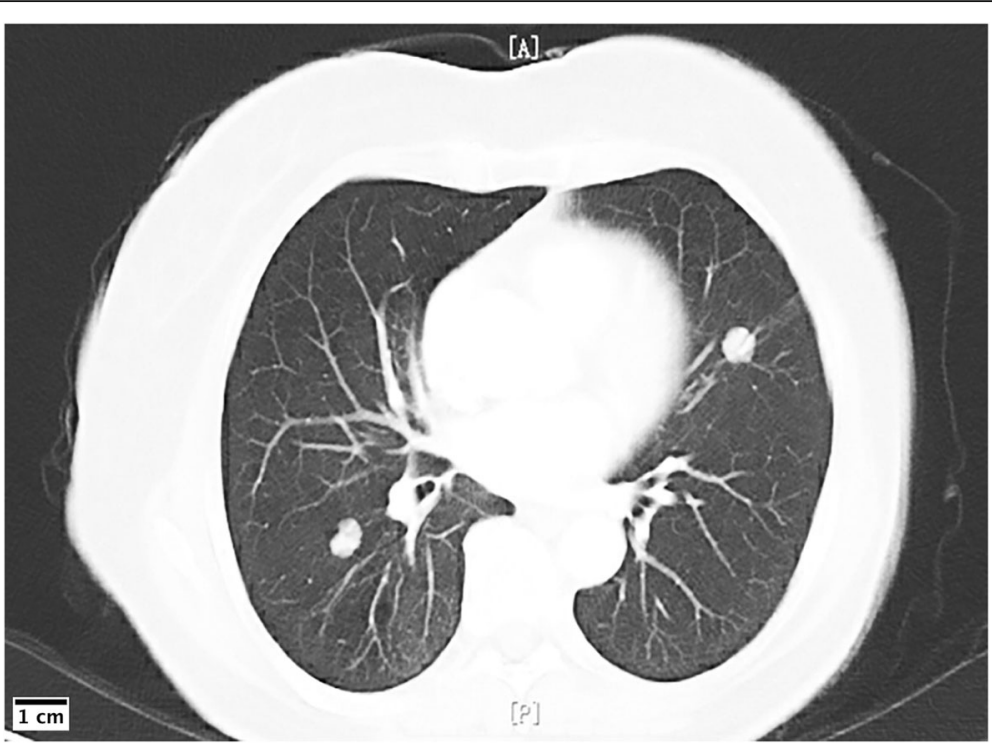

Fig. 1 A computerized tomography chest scan showing multiple bilateral pulmonary nodules (Case 1)

changes with pseudopapillary formation (Case1; Fig. 3c) and gland-like structures (Case 5; Fig. 3d) were observed within the tumor nests. Glands were also seen, although such structures were entrapped in non-neoplastic ducts (Case 6; Fig. 3e). In addition, tumors in oral sites were potentially connected to the mucosal surface epithelium and exhibited squamous epithelial hyperplasia (Case 7; Fig. 3f).

The tumor cells were separated by stroma that appeared hyaline (Case 1; Fig. 2c), fibrocellular (Case 2; Fig. 2a), and myxoid (Case 5; Fig. 3d). Occasionally, hemorrhages (Case 4; Fig. 4a) and lymphoid infiltration (Case 3; Fig. 4b, c) were also observed around the tumor nests.

\section{Immunohistochemical results}

The IHC detection results are shown in Table 2. All the cases consistently expressed p63 (Case 1; Fig. 5a), p40, and CK5/6 (Case 1; Fig. 5b), while myoepithelial markers were uniformly negative, including SMA (Case 2; Fig. 5c), calponin (Case 3; Fig. 5d), S-100 protein (Case 2; Fig. 5e), GFAP, and CD10. SOX10 (Case 2; Fig. 5f) was also consistently negative in all cases. In Case 3 , the left tonsil case, p16 was negative (Case 3, Fig. 5g). In Case 1, p53 showed a wild-type expression pattern in the HGT region, like the conventional region (not shown). CCCs from the nasal cavity, left tonsil, and left maxillary sinus (Cases 2, 3, and 4, respectively) were also detected with
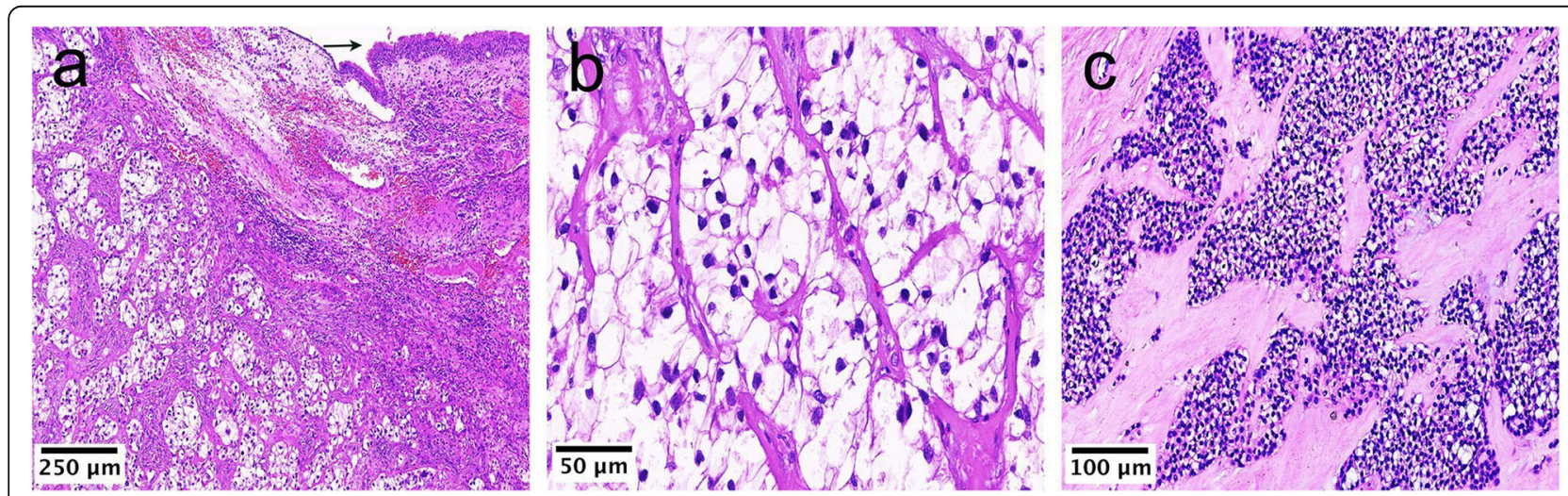

Fig. 2 The typical histological morphology for CCC. (a) Ciliated columnar epithelium of the respiratory tract is observed at the upper right margin (arrow). The CCC was located beneath the mucosa (Case 2, HE $\times 100$ ). (b) Tumors were typically composed of oval, round, and polygonal cells with clear cytoplasm, arranged in nests or sheets, surrounded by fibrocellular stroma (Case 2, HEX 400). (c) In the conventional low-grade region of the HGT case, nuclei were uniform and small, round or oval, and had irregular, indented contours with finely dispersed or dark condensed chromatin (Case 1, HEX 200) 


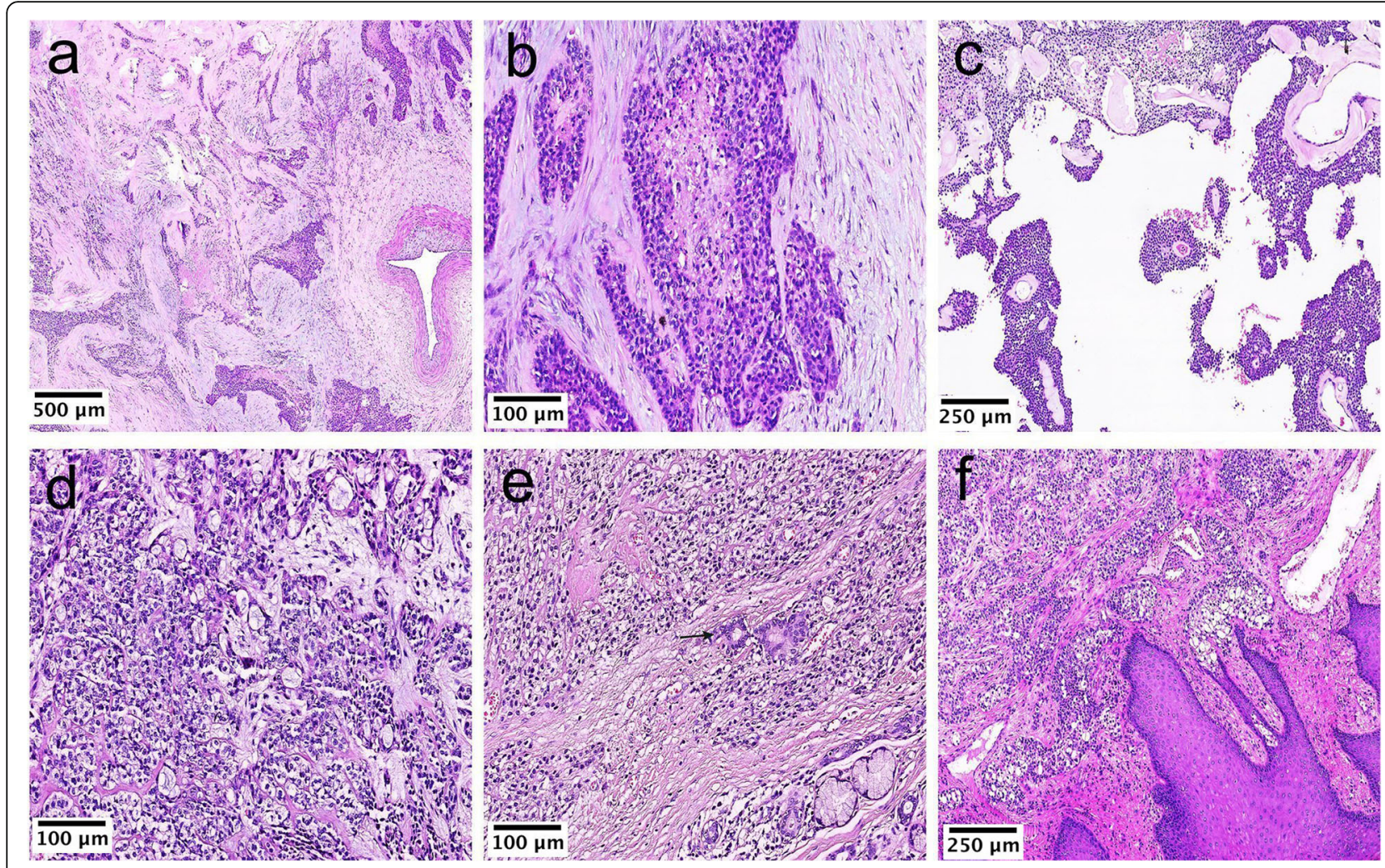

Fig. 3 Uncommon histological morphology in CCC. (a) The morphological contrast between the conventional low-grade region on the left and the HGT region on the right and the middle (Case 1, HEX 50). (b) The HGT area showing nuclear pleomorphisms, high nuclear-to-cytoplasmic ratios, high mitotic activity, and necrosis (Case 1, HEX 200). (c) Cystic changes were observed within the tumor nest, forming pseudopapillae (Case 1, HEx 100). (d) Gland-like spaces were focally identified (Case 5, HEx 200). (e) Entrapped non-neoplastic ducts (arrow) (Case 6, HEx 200). (f) Tumor cells were connected to the surface overlying epithelium (Case 7, HEX 100)

a large immunostaining panel (not shown) to confirm the diagnosis.

Ki-67 proliferation index was calculated for each field. Ten high-power fields (HPF) were arbitrarily selected and the median value was calculated. In the CCC case with HGT (Case 1), where staining was performed, there was a striking distinction between the Ki-67 index for the low-grade versus the high-grade components, with a low index (median, 1.9\%) in the former and a high index (median, 42.5\%) (Fig. 5h) in the latter.

\section{FISH detection results}

The FISH detection results are shown in Table 3 . EWSR1 rearrangement (Case 1; Fig. 6a) was positive in
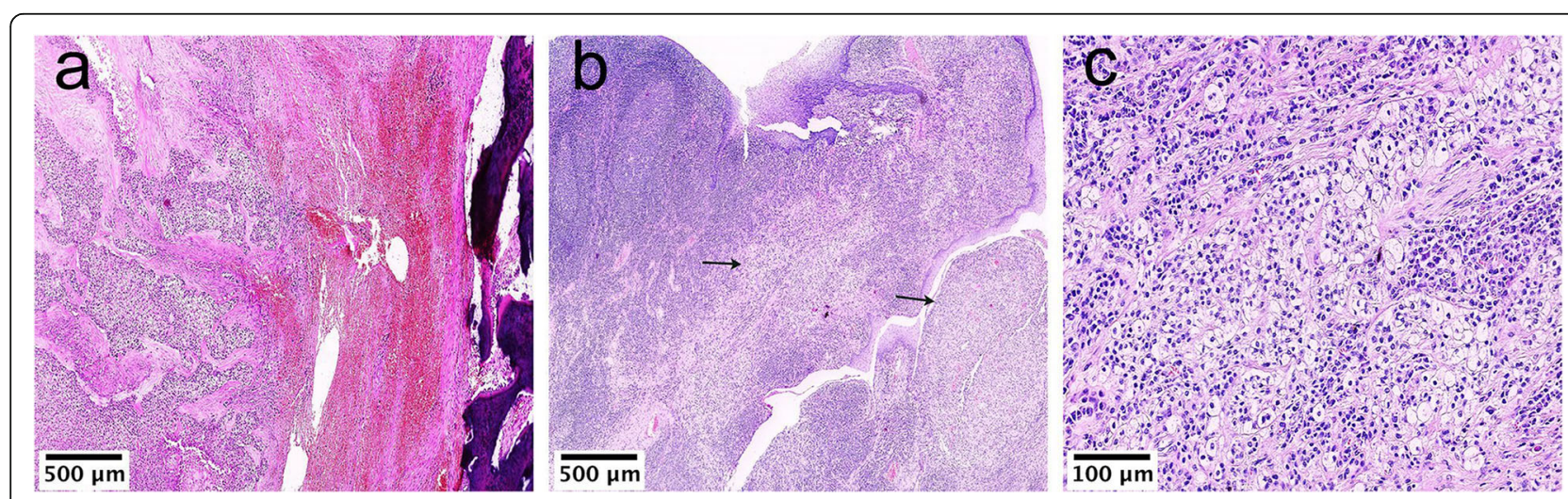

Fig. 4 Uncommon stromal alterations in CCC. (a) Stromal hemorrhage (Case 4, HEX 50). (b, c) Lymphoid infiltration around the tumor nests (the arrows indicate tumor cells) (Case 3, HEX 50 and HEX 200) 
Table $\mathbf{2} \mathrm{IHC}$ detection results in 10 cases of CCC

\begin{tabular}{|c|c|c|c|c|c|c|c|c|c|c|c|c|}
\hline NO & Site & p63 & p40 & CK5/6 & SMA & Calponin & $S-100$ & GFAP & CD10 & SoX10 & $\mathrm{p} 16$ & p53 \\
\hline 1 & Right submandibular gland & + & + & + & - & - & - & - & - & - & ND & W-T \\
\hline 2 & Nasal cavity & + & + & + & - & - & - & - & - & - & ND & ND \\
\hline 3 & Left tonsil & + & + & + & - & - & - & - & - & - & - & ND \\
\hline 4 & Left maxillary sinus & + & + & + & - & - & - & - & - & - & ND & ND \\
\hline 5 & Root of the tongue & + & + & + & - & - & - & - & - & - & ND & ND \\
\hline 6 & Base of tongue & + & + & + & - & - & - & - & - & - & ND & ND \\
\hline 7 & Right hard palate & + & + & + & - & - & - & - & - & - & ND & ND \\
\hline 8 & Right hard palate & + & + & + & - & - & - & - & - & - & ND & ND \\
\hline 9 & Right hard palate & + & + & + & - & - & - & - & - & - & ND & ND \\
\hline 10 & Left hard palate & + & + & + & - & - & - & - & & - & ND & ND \\
\hline
\end{tabular}

IHC Immunohistochemistry, ND not done, $W$ - $T$ wild-type expression

all cases. Four cases (Cases 1, 2, 3, and 4) were positive (4/5) for EWSR1-ATF1 fusion (Case 1; Fig. 6b). MAML2 rearrangement was tested in three cases (Cases 7,9 , and $10)$, all of which showed no re-arrangement (0/3, not shown). The FISH assay revealed EWSR1 rearrangement in the CCC case with HGT, and this molecular alteration was confirmed in both conventional and HGT regions.

\section{Discussion}

In the 2017 WHO classification of head and neck tumors, CCC was defined as a low-grade salivary gland malignancy composed of tumor cells with clear cytoplasm [2], rather than as a clear cell carcinoma. It has been classified as "not otherwise specified" (NOS), as it lacks clear clinicopathological features and was initially considered a diagnosis of exclusion in the 2005 WHO classification. Recent molecular genetic data has gradually revealed the genetic background of CCC and enabled greater understanding and broadening of its morphological spectrum, which has contributed to its removal from the NOS classification and increased its recognition as a rare malignancy that can undergo HGT and occur at uncommon sites.

The clinical symptoms of CCC depend on the lesion location, and the main clinical symptoms in our cohort included the development of a painless, firm mass, epistaxis, paresthesia, ulceration, and dysphagia. When
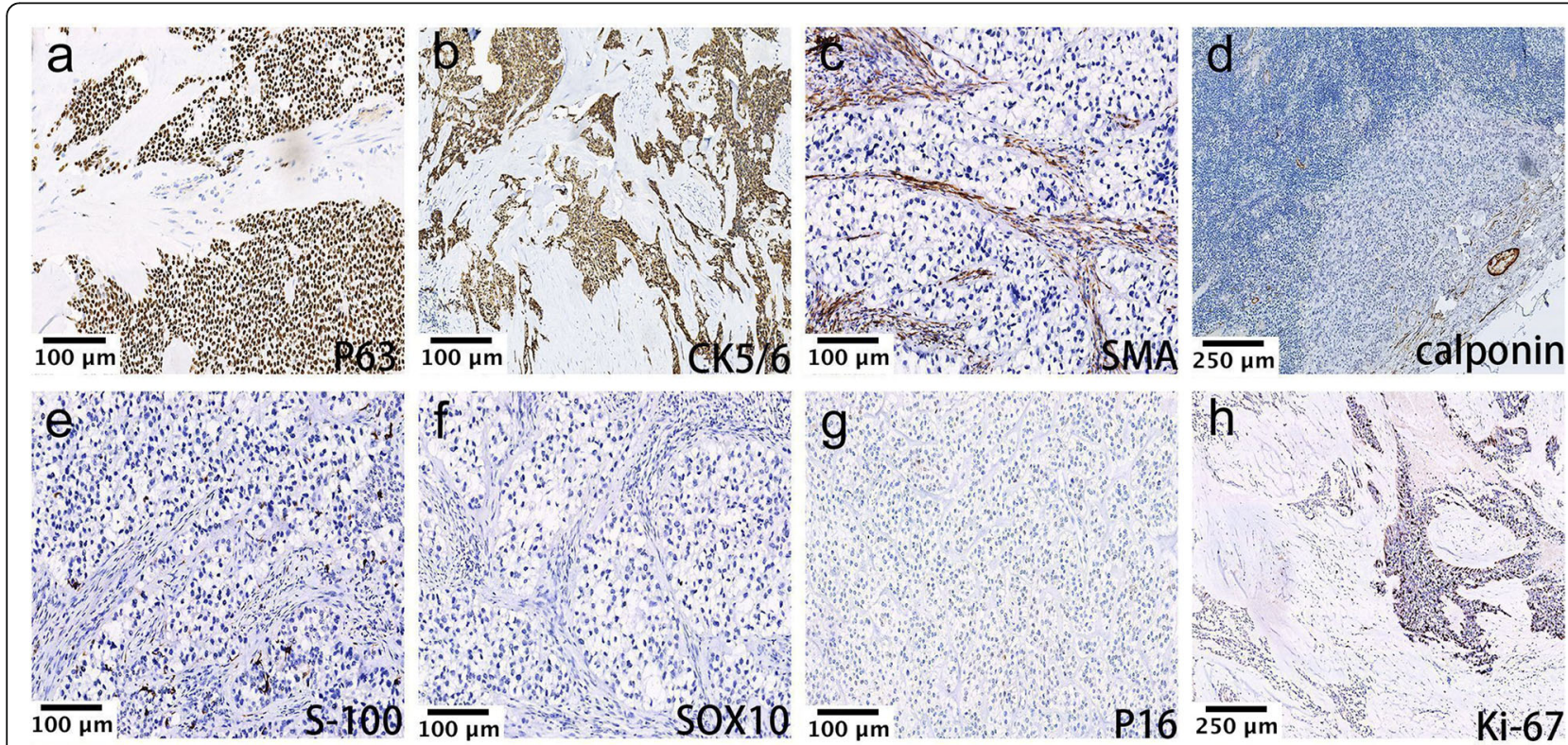

Fig. $5 \mathrm{HC}$ for the CCC. The tumor cells were positive for (a) p63 (Case 1, IHC $\times 200$ ) and (b) CK5/6 (Case 1, IHC × 200), and negative for (c) SMA (Case 2, IHC × 200), (d) calponin (Case 3, IHC × 100), (e) S-100 protein (Case 2, IHC $\times 200$ ), and (f) SOX10 (Case 2, IHC $\times 200$ ). (g) p16 expression was negative (Case 3, IHC $\times$ 200). (h) Different Ki-67 immunoreactivity was noted between the conventional region in the lower left corner (median, 1.9\%) and the HGT region in the upper right corner (median, 42.5\%) (Case 1, IHC $\times 100$ ) 
Table 3 FISH detection results in 10 cases of CCC

\begin{tabular}{lllll}
\hline NO & Site & EWSR1 & EWSR1-ATF1 & MAML2 \\
\hline 1 & Right submandibular gland & + & + & ND \\
2 & Nasal cavity & + & + & ND \\
3 & Left tonsil & + & + & ND \\
4 & Left maxillary sinus & + & + & ND \\
5 & Root of the tongue & + & ND & ND \\
6 & Base of tongue & + & - & ND \\
7 & Right hard palate & + & ND & - \\
8 & Right hard palate & + & ND & ND \\
9 & Right hard palate & + & ND & - \\
10 & Left hard palate & + & ND & - \\
\hline
\end{tabular}

FISH fluorescence in situ hybridization, $N D$ not done

CCC appears as a painless mass, it is typically ignored by patients. Case 1 documented a painless mass arising in the right submandibular gland, which was considered benign after fine needle aspiration, so no further surgery was performed. After an uneventful 20 years, the mass began to enlarge rapidly and painfully, and was diagnosed as CCC with HGT after resection. Therefore, the rapid enlargement of a longstanding tumor suggests the possibility of increased malignancy, especially if accompanied by a sudden onset of pain. To our knowledge, this is the first case of HGT detected by FISH testing, arising in the submandibular gland after such a long history.

HGT is a rare event that has been described in a variety of salivary gland malignancies, including adenoid cystic carcinoma, acinic cell carcinoma, epithelial-myoepithelial carcinoma (EMC), and low-grade MEC [11-14]. HGT is an exceedingly rare phenomenon in CCC; only two cases of HGT $[6,7]$ have been reported so far, and only one has been confirmed by molecular testing [7]. The clinicopathological and molecular features of the cases previously published and of the current HGT case are summarized as follows. First, HGT may occur at the initial presentation or result from malignant progression in patients with a longstanding disease course. Second, it exhibits aggressive clinical behavior, and the lung is a common metastatic site. Third, focal regions, at least, display moderate to severe nuclear aplasia, frequent or atypical mitotic figures, and necrosis. Fourth, conventional and HGT regions coexist, and both components share the same molecular alterations (EWSR1 rearrangement), providing reliable evidence that the HGT component represents a transformation of CCC, rather than the coexistence with another SGT. However, it is noteworthy that not all CCCs with aggressive behavior show HGT or poorly differentiated morphologies, and there is currently no histological grading system to predict the aggressive behavior in tumors [15], making further investigation worthwhile. In HGT cases, p53 showed wild type expression in HGT areas, inconsistent with previous reports where adenoid cystic carcinoma and MEC with HGT showed mutant type expression patterns for this marker $[11,16]$, suggesting that the mechanism by which HGT occurs in CCC needs further investigation.

CCC was initially termed HCCC due to the prominent stromal hyalinization. Although the stroma of most CCCs exhibits hyalinization, CCC does not always present with this morphology, sometimes exhibiting a fibrocyte-rich stroma or loose mucinous matrix in some cases. For example, the neoplastic stroma was fibrous with focal mucinous changes in Cases 2, 3, and 9. CCC was adopted as the formal name by the 2017 WHO classification of head and neck tumors, with HCCC as its synonym. We suggest that it is appropriate to include HCCC as a subtype of CCC, as these tumors share the same molecular alterations (EWSR1 rearrangement), regardless of whether their stroma are hyalinized.

Advances in the molecular genetics of SGTs have facilitated the discovery of other genes as the novel EWSR1
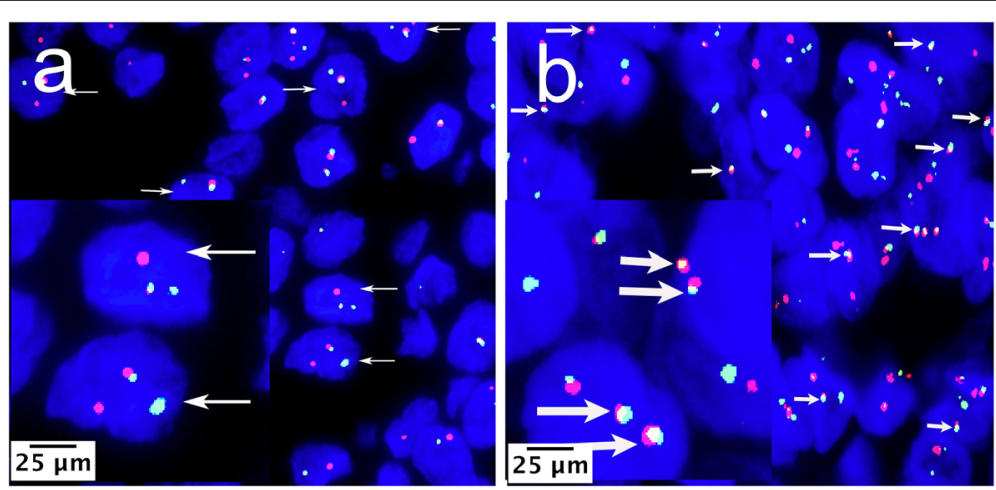

Fig. 6 FISH for CCC. (a) FISH with EWSR1 break-apart probe. The break-apart probe shows one separate red and green signal per cell (arrows) was considered positive for EWSR1 rearrangement; the fused red-green (yellow) signal was considered normal (Case 1, FISH× 1000). (b) FISH with EWSR1-ATF1 fusion probe. Showing at least one red-green (yellow) fusion signal per cell (arrows) was considered as EWSR1-ATF1 fusion positive (Case 1, FISH×1000) 
fusion partners in CCCs. Although it is well documented that the EWSR1-ATF1 fusion occurs in most CCCs [1, 2], a small proportion of cases showed other molecular rearrangements; notably, Chapman et al. [17] recently described three cases with EWSR1-CREM fusion. In our cohort, all cases had EWSR1 rearrangements, as confirmed by FISH testing, and four of five cases harbored EWSR1-ATF1 fusions, while one case did not, suggesting that EWSR1 might have had another partner gene.

CCCs show a predilection for the oral cavity. However, it is important to note that this cancer can also occur in uncommon sites, such as the nasal cavity, left tonsil, and left maxillary sinus, as observed in our cohort (Cases 2, 3 , and 4). Approximately 50 cases of CCC at these uncommon sites have been reported in the English literature, but some cases have not been genetically confirmed [18-22]. The differential diagnosis of CCCs arising in these rare sites is different from that of tumors occurring at common sites. Thus, a greater general awareness of rare tumors arising in uncommon sites is required, as these are particularly susceptible to misdiagnosis.

Differential diagnosis is very challenging when CCCs occur at uncommon sites. In Case 2, CCC arising in the nasal cavity had to be differentiated from renal cell-like sinonasal adenocarcinoma, which is composed of glands lined by cuboidal cells with clear cytoplasm. However, Case 2 was positive for p63, p40, and CK5/6 and harbored the EWSR1 translocation, characteristics which renal cell-like sinonasal carcinoma does not express. Case 3 involved the left tonsil and needed to be differentiated from human papilloma virus (HPV)-related squamous cell carcinoma (SCC), which occurs more frequently in the oropharynx.

The use of p16 IHC staining, typically used as a surrogate marker for HPV in SCC of the head and neck, to distinguish between tumor types would likely lead to misdiagnosis. Bishop et al. [23] reported that p16 is frequently expressed in CCC, with more than $70 \%$ of tumor cells staining positive in some tumors. Therefore, p16 staining positivity should not be considered a useful tool to distinguish between CCC and HPV-related SCC. Fortunately, p16 staining was negative in our case, so we did not need further HPV RNA testing. Case 3, arising in the maxillary sinus, needed to be differentiated from clear cell variant squamous cell carcinoma (CCSCC) because it demonstrated a squamous immunophenotype; however, it lacked squamous dysplasia/carcinoma-in-situ and exhibited less nuclear pleomorphism than in CCSC C. Thus, testing for EWSR1 rearrangement and/or EWSR1-ATF1 fusion could be helpful in cases at uncommon sites.

In addition to the above differential diagnoses, CCCs can be differentiated from other clear cell rich-SGTs. In the case of clear cell MC, discrimination is essential because MCs with EWSR1 rearrangement exhibit aggressive clinical behaviors and have poor clinical outcomes compared with CCCs [24]. Traditionally, EWSR1 rearrangements were considered specific to CCCs but have since been confirmed in MCs [24, 25]. Moreover, CCCs were initially believed to be negative for myoepithelial markers; however, a minor subset of CCCs confirmed by ATF1 rearrangement exhibited S-100 and/or SOX10 immunoreactivity [25]. Thus, distinguishing between CCCs expressing myoepithelial markers and MCs with ATF1 rearrangements requires further study. Fortunately, all cases here were negative for a panel of myoepithelial markers (SMA, calponin, S-100 protein, GFAP, and $\mathrm{CD} 10)$. In addition, SOX10, a transcription factor that plays a key role in the differentiation of the neural crest, maintenance of Schwann cells and melanocytes, and that was recently found to be expressed in myoepithelial tumors [26], was also not detected. These results virtually excluded the possibility of MC.

An additional SGT that warrants differential diagnosis is MEC. Mucicarmine negativity is typically used to distinguish CCC from clear cell variant MEC. However, intracellular mucin may be present in approximately $30 \%$ of CCC tumors [2, 27]. Fortunately, these two tumor types have different molecular alterations, with MECs typically exhibiting MAML2-CRTC1 or MAML2-CRTC3 fusion. Cases 7, 9, and 10 were submitted for confirmation by molecular testing, with a preliminary diagnosis of MEC. However, MAML2 was intact, and EWSR1 translocation was detected, confirming the diagnosis for CCC. These three cases correspond with previous reports that MECs with EWSR1 rearrangements but no MAML2 fusion were in fact CCCs [27]. Moreover, tumors in cases 7 and 10 arose from the overlying mucosal epithelium, which has never been described for MEC, and may aid in distinguishing these tumor types. EMC, another SGT, resembles CCC when it is predominantly composed of clear cells; however, CCC lacks the biphasic pattern of EMC. In addition, HRAS mutations have a high diagnostic value for EMC [28] but not CCC.

Importantly, CCCs should be differentiated from odontogenic tumors. EWSR1-ATF1 and EWSR1-CREM fusions are found in both CCC and clear cell odontogenic carcinoma (CCOC) [22, 29-32], and there is overlap in histomorphology and immunophenotypes, with the exception that CCOC occurs in the jaw. These findings highlight the biological link between them, and whether they are the same entity occurring at different locations is still under debate. In our cohort, the possibility of CCOC was excluded by imaging analysis.

In addition to primary tumors, metastatic clear cell renal cell carcinoma needs to be ruled out. The renal 
tumor is immunoreactive for RCC (renal cell carcinoma marker), PAX8, and CD10, which were all negative in the CCCs investigated here.

CCC mostly behaves indolently, and treatment typically involves complete excision. Postoperative radiotherapy can be used in patients with positive margins, recurrent or more aggressive disease, or $\operatorname{HGT}[6,7,18]$. However, the efficacy of radiotherapy and/or chemotherapy is unclear, although some patients have received these treatments [33]. Case 1 (HGT) received postoperative chemotherapy. Cases 4,8 , and 10 received radiotherapy after surgery, without evidence of disease at follow-ups of 88,11 , and 54 months, respectively. The remaining five patients remained disease-free at 8 - and 80-month follow-ups, despite having received no additional therapy after surgery. Therefore, the prognosis of $\mathrm{CCC}$ is generally good, but the late onset of local recurrence and distant metastases have been sporadically recorded [34-36], suggesting the need for long-term follow-ups.

The present study has certain limitations. Comprehensive molecular studies should be performed, and alternative next-generation sequencing techniques may, for example, detect other partner genes of EWSR1 in addition to ATF1 and CREM. However, it is generally believed that a definitive diagnosis can be made by combining salient histological features, immunophenotypes, and molecular testing.

In summary, the general awareness of CCCs with HGT and those arising in uncommon locations needs to be increased, as these are particularly likely to be misdiagnosed. Sudden and rapid expansion of a longstanding CCC case should be a forewarning of the possibility of HGT. Our results showing the same immunophenotypic and molecular alterations (EWSR1 rearrangement) in the HGT area and conventional areas of CCC provide reliable evidence that the HGT component represented a transformation of CCC rather than the coexistence of another SGT. CCCs need to be differentiated from many other clear cell-rich tumors, and their diagnosis needs to be confirmed by combining morphology-based IHC staining with molecular detection. Notably, CCCs do not always have a hyalinized stroma, which has led to the proposal of using the term HCCC to denote a subtype of CCC. Finally, CCCs generally have a good prognosis according to our follow-up data, except for the HGT case, which needs continued treatment.

\section{Abbreviations}

CCC: Clear cell carcinoma; HGT: High-grade transformation; IHC: Immunohistochemistry; FISH: Fluorescence in situ hybridization; HCCC: Hyalinizing clear cell carcinoma; SGT: Salivary gland tumor; MEC: Mucoepidermoid carcinoma; WHO: World Health Organization; HE: Hematoxylin and eosin; FFPE: Formalin-fixed paraffin-embedded; CT: Computed tomography; SCC: Squamous cell carcinoma; CCSCC: Clear cell variant squamous cell carcinoma; MC: Myoepithelial carcinoma; CCOC: Clear cell odontogenic carcinoma

\section{Acknowledgements}

The authors would like to thank the staff of the Department of Pathology at Beijing Tongren Hospital for preparing the histological sections.

\section{Authors' contributions}

LX performed the histological examination and drafted the manuscript, SW and JW participated in data analysis, JY provided tissue specimens, HL designed the study. All authors read and approved the final manuscript.

\section{Funding}

This study was supported by the Beijing Municipal Administration of Hospitals Clinical Medicine Development of Special Funding (ZYLX201814).

\section{Availability of data and materials}

The datasets used are available from the corresponding author on reasonable request.

\section{Declarations}

\section{Ethics approval and consent to participate}

This study was approved by the Institute Research Ethics Committee of Beijing Tongren Hospital (Approval No. TRECKY2021-108) and written informed consent was obtained from the patients.

\section{Consent for publication}

Not applicable.

\section{Competing interests}

The authors declare that they have no competing interests.

\section{Author details}

'Department of Pathology, Anqing Hospital, Anhui Medical University, Anqing Municipal Hospital, Anqing 246003, China. ${ }^{2}$ Department of Pathology, Beijing Tongren Hospital, Capital Medical University, Beijing Key Laboratory of Head and Neck Molecular Diagnostic Pathology, Beijing 100730, China. ${ }^{3}$ Department of Pathology, Yantai Yuhuangding Hospital of Qingdao University, Yantai 264000, Shandong, China. ${ }^{4}$ Department of Pathology, Shaoxing People's Hospital, Shaoxing 312000, China. ${ }^{5}$ Department of Oncology Surgery, Anqing Hospital, Anhui Medical University, Anqing Municipal Hospital, Anqing 246003, China.

Received: 18 October 2021 Accepted: 15 January 2022

Published online: 30 January 2022

\section{References}

1. Milchgrub S, Gnepp DR, Vuitch F, Delgado R, Albores-Saavedra J. Hyalinizing clear cell carcinoma of salivary gland. Am J Surg Pathol. 1994;18(1):74-82. https://doi.org/10.1097/00000478-199401000-00007.

2. El-Naggar AK, Chan JKC, Grandis JR, Takata T, Slootweg PJ. World Health Organization classification of head and neck tumours. 4th ed. Lyon: IARC; 2017. p. 168-9.

3. Shah AA, LeGallo RD, van Zante A, Frierson HF Jr, Mills SE, Berean KW, et al. EWSR1 genetic rearrangements in salivary gland tumors: a specific and very common feature of hyalinizing clear cell carcinoma. Am J Surg Pathol. 2013; 37(4):571-8. https://doi.org/10.1097/PAS.0b013e3182772a15.

4. Antonescu CR, Katabi N, Zhang L, Sung YS, Seethala RR, Jordan RC, et al. EWSR1-ATF1 fusion is a novel and consistent finding in hyalinizing clear-cell carcinoma of salivary gland. Genes Chromosomes Cancer. 2011;50(7):55970. https://doi.org/10.1002/gcc.20881.

5. Nakano T, Yamamoto H, Nishijima T, Tamiya S, Shiratsuchi H, Nakashima T, et al. Hyalinizing clear cell carcinoma with EWSR1-ATF1 fusion gene: report of three cases with molecular analyses. Virchows Arch. 2015;466(1):37-43. https://doi.org/10.1007/s00428-014-1676-5.

6. O'Regan E, Shandilya M, Gnepp DR, Timon C, Toner M. Hyalinizing clear cell carcinoma of salivary gland: an aggressive variant. Oral Oncol. 2004;40(3): 348-52. https://doi.org/10.1016/j.oraloncology.2003.08.023.

7. Jin R, Craddock KJ, Irish JC, Perez-Ordonez B, Weinreb I. Recurrent hyalinizing clear cell carcinoma of the base of tongue with high-grade 
transformation and EWSR1 gene rearrangement by FISH. Head Neck Pathol. 2012;6(3):389-94. https://doi.org/10.1007/s12105-012-0338-7.

8. Singh N, Piskorz AM, Bosse T, Jimenez-Linan M, Rous B, Brenton JD, et al. p53 immunohistochemistry is an accurate surrogate for TP53 mutational analysis in endometrial carcinoma biopsies. J Pathol. 2020;250(3):336-45. https://doi.org/10.1002/path.5375.

9. Papp G, Mihály D, Sápi Z. Unusual signal patterns of break-apart FISH probes used in the diagnosis of soft tissue sarcomas. Pathol Oncol Res. 2017;23(4):863-71. https://doi.org/10.1007/s12253-017-0200-z.

10. Machado I, Noguera R, Pellin A, Lopez-Guerrero JA, Piqueras M, Navarro S, et al. Molecular diagnosis of Ewing sarcoma family of tumors: a comparative analysis of 560 cases with FISH and RT-PCR. Diagn Mol Pathol. 2009;18(4): 189-99. https://doi.org/10.1097/PDM.0b013e3181a06f66.

11. Seethala RR, Hunt JL, Baloch ZW, Livolsi VA, Leon Barnes EL. Adenoid cystic carcinoma with high-grade transformation: a report of 11 cases and a review of the literature. Am J Surg Pathol. 2007;31 (11):1683-94. https://doi. org/10.1097/PAS.0b013e3180dc928.

12. Skálová A, Sima R, Vanecek T, Muller S, Korabecna M, Nemcova J, et al. Acinic cell carcinoma with high-grade transformation: a report of 9 cases with immunohistochemical study and analysis of TP53 and HER-2/neu genes. Am J Surg Pathol. 2009;33(8):1137-45. https://doi.org/10.1097/PAS. 0b013e3181a38e1c.

13. Roy P, Bullock MJ, Perez-Ordoñez B, Dardick I, Weinreb I. Epithelialmyoepithelial carcinoma with high grade transformation. Am J Surg Pathol. 2010;34(9):1258-65. https://doi.org/10.1097/PAS.0b013e3181e366d2.

14. Nagao T, Gaffey TA, Kay PA, Unni KK, Nascimento AG, Sebo TJ, et al. Dedifferentiation in low-grade mucoepidermoid carcinoma of the parotid gland. Hum Pathol. 2003;34(10):1068-72. https://doi.org/10.1053/S0046-81 77(03)00418-0.

15. Daniele L, Nikolarakos D, Keenan J, Schaefer N, Lam AK. Clear cell carcinoma, not otherwise specified/hyalinising clear cell carcinoma of the salivary gland: the current nomenclature, clinical/pathological characteristics and management. Crit Rev Oncol Hematol. 2016;102:55-64. https://doi.org/1 0.1016/..critrevonc.2016.03.018

16. Subramaniam MM, Ng SB, Seah SB, Anuar D, Soong R, Lee VK. Molecular characterization of dedifferentiated mucoepidermoid carcinoma of the trachea using laser microdissection-based TP53 mutation analysis. Histopathology. 2009;55(4):472-5. https://doi.org/10.1111/j.1365-2559.2009. 03385.x.

17. Chapman E, Skalova A, Ptakova N, Martinek P, Goytain A, Tucker T, et al. Molecular profiling of hyalinizing clear cell carcinomas revealed a subset of tumors harboring a novel EWSR1-CREM fusion: report of 3 cases. Am I Surg Pathol. 2018;42(9):1182-9. https://doi.org/10.1097/PAS.0000000000001114.

18. Oliver J, Wu P, Chang C, Roden D, Wang B, Liu C, et al. Patterns of care and outcome of clear cell carcinoma of the head and neck. Otolaryngol Head Neck Surg. 2019;161(1):98-104. https://doi.org/10.1177/0194599819835779.

19. Gubbiotti MA, Montone K, Zhang P, Livolsi V, Baloch Z. A contemporary update on hyalinizing clear cell carcinoma: compilation of all in-house cases at our institution and a literature review spanning 2015-2020. Hum Pathol. 2021;111:45-51. https://doi.org/10.1016/j.humpath.2021.01.007.

20. AlAli BM, Alyousef MJ, Kamel AS, Al Hamad MA, Al-Bar MH, Algowiez RM. Primary paranasal sinus hyalinizing clear cell carcinoma: a case report. Diagn Pathol. 2017:12(1):70. https://doi.org/10.1186/s13000-017-0659-7.

21. Imai T, Satoh I, Matsumoto K, Ito S, Asada Y, Kato K, et al. Clear cell carcinoma of the nasal cavity: a case report from histopathological viewpoint. Auris Nasus Larynx. 2016;43(1):108-11. https://doi.org/10.1016/j.a nl.2015.06.002

22. Ceballos Sáenz C, Argyris PP, Manivel JC, Urias Barreras CM, Koutlas IG. Nasopharyngeal hyalinizing clear cell carcinoma: report of the histopathologic features of a case showing EWSR1 rearrangements by FISH and literature review. Int J Surg Pathol. 2014;22(7):667-72. https://doi.org/1 $0.1177 / 1066896914526778$

23. Bishop JA, Rooper LM, Chiosea SI, Westra WH. Clear cell carcinoma of salivary glands is frequently p16 positive: a pitfall in the interpretation of oropharyngeal biopsies. Am J Surg Pathol. 2018;42(3):367-71. https://doi. org/10.1097/PAS.0000000000000977.

24. Skálová A, Weinreb I, Hyrcza M, Simpson RHW, Laco J, Agaimy A, et al. Clear cell myoepithelial carcinoma of salivary glands showing EWSR1 rearrangement: molecular analysis of 94 salivary gland carcinomas with prominent clear cell component. Am J Surg Pathol. 2015;39(3):338-48. https://doi.org/10.1097/PAS.0000000000000364.
25. Skálová A, Agaimy A, Vanecek T, Baněčková M, Laco J, Ptáková N, et al. Molecular profiling of clear cell myoepithelial carcinoma of salivary glands with EWSR1 rearrangement identifies frequent PLAG1 gene fusions but no EWSR1 fusion transcripts. Am J Surg Pathol. 2021;45(1):1-13. https://doi. org/10.1097/PAS.0000000000001591.

26. Ohtomo R, Mori T, Shibata S, Tsuta K, Maeshima AM, Akazawa C, et al. SOX10 is a novel marker of acinus and intercalated duct differentiation in salivary gland tumors: a clue to the histogenesis for tumor diagnosis. Mod Pathol. 2013;26(8):1041-50. https://doi.org/10.1038/modpathol.2013.54.

27. Hsieh MS, Wang H, Lee YH, Ko JY, Chang YL. Reevaluation of MAML2 fusion-negative mucoepidermoid carcinoma: a subgroup being actually hyalinizing clear cell carcinoma of the salivary gland with EWSR1 translocation. Hum Pathol. 2017;61:9-18. https://doi.org/10.1016/j.humpath.2 016.06.029.

28. El Hallani S, Udager AM, Bell D, Fonseca I, Thompson LDR, Assaad A, et al. Epithelial-myoepithelial carcinoma: frequent morphologic and molecular evidence of preexisting pleomorphic adenoma, common HRAS mutations in PLAG1-intact and HMGA2-intact cases, and occasional TP53, FBXW7, and SMARCB1 alterations in high-grade cases. Am J Surg Pathol. 2018;42(1):1827. https://doi.org/10.1097/PAS.0000000000000933.

29. Bilodeau EA, Weinreb I, Antonescu CR, Zhang L, Dacic S, Muller S, et al. Clear cell odontogenic carcinomas show EWSR1 rearrangements: a novel finding and a biological link to salivary clear cell carcinomas. Am J Surg Pathol. 2013;37(7):1001-5. https://doi.org/10.1097/PAS.0b013e31828a6727.

30. Vogels R, Baumhoer D, van Gorp J, Eijkelenboom A, Verdijk M, van Cleef P, et al. Clear cell odontogenic carcinoma: occurrence of EWSR1-CREB1 as alternative fusion gene to EWSR1-ATF1. Head Neck Pathol. 2019;13(2):22530. https://doi.org/10.1007/s12105-018-0953-z.

31. Santana T, de Andrade FL, de Sousa Melo MC, da Rocha GBL, Trierveiler M. Clear cell odontogenic carcinoma harboring the EWSR1-ATF1 fusion gene: report of a rare case. Head Neck Pathol. 2020;14(3):847-51. https://doi.org/1 0.1007/s12105-019-01103-4.

32. Lan J, Huang SC, Chen YH, Chen WC, Jin YT, Lu YC, et al. Primary paranasal sinus clear cell carcinoma with EWSR1-ATF1 fusion: report of 2 molecularly confirmed cases exhibiting unique histopathology. Hum Pathol. 2017;63: 139-43. https://doi.org/10.1016/j.humpath.2016.09.036.

33. Yang XH, Liu L, Shi YY, Hu YJ, Hu QG, Zhang P. Hyalinizing clear cell carcinoma of salivary gland origin in the head and neck: clinical and histopathological analysis. Int J Oral Maxillofac Surg. 2018;47(6):692-8. https://doi.org/10.1016/j.jjom.2017.11.004.

34. Su HK, Wang BY, Mannan AASR, Dewey EH, Alpert EH, Dos Reis LL, et al. Very delayed cervical lymph node metastases from hyalinizing clear cell carcinoma: report of 2 cases. Head Neck. 2015;37(2):E19-21. https://doi.org/1 $0.1002 /$ hed. 23764

35. Yamashita K, Kawakami F, Nakashima Y, Murakami K. Clear cell carcinoma of the minor salivary gland: an autopsy case with multiple metastases 29 years after the initial surgery and a review of the literature. Oral Surg Oral Med Oral Pathol Oral Radiol Endod. 2009;107(6):819-25. https://doi.org/10.1016/j. tripleo.2009.01.034.

36. Gon S, Bhattacharyya A, Majumdar B, Das TK. Post-radiotherapy locoregional recurrence of hyalinizing clear cell carcinoma of palate. J Cancer Res Ther. 2013;9(2):281-3. https://doi.org/10.4103/0973-1482.113386.

\section{Publisher's Note}

Springer Nature remains neutral with regard to jurisdictional claims in published maps and institutional affiliations.

\section{Ready to submit your research? Choose BMC and benefit from:}

- fast, convenient online submission

- thorough peer review by experienced researchers in your field

- rapid publication on acceptance

- support for research data, including large and complex data types

- gold Open Access which fosters wider collaboration and increased citations

- maximum visibility for your research: over $100 \mathrm{M}$ website views per year

At BMC, research is always in progress.

Learn more biomedcentral.com/submissions 